\title{
Adjunctive brexpiprazole in patients with major depressive disorder and anxiety symptoms: post hoc analyses of three placebo-controlled studies
}

This article was published in the following Dove Press journal: Neuropsychiatric Disease and Treatment

\author{
Michael E Thase' \\ Emmanuelle Weiller ${ }^{2}$ \\ Peter Zhang ${ }^{3}$ \\ Catherine Weiss ${ }^{4}$ \\ Roger S Mclntyre ${ }^{5}$
}

'Department of Psychiatry, Perelman School of Medicine, University of Pennsylvania and the Philadelphia Veterans Affairs Medical Center, Philadelphia, PA, USA; ${ }^{2}$ Medical Affairs, H. Lundbeck A/S, Valby, Copenhagen, Denmark; ${ }^{3}$ Biostatistics Department, Otsuka Pharmaceutical Development and Commercialization Inc., Princeton, NJ, USA; ${ }^{4}$ Global Medical Affairs, Otsuka Pharmaceutical Development and Commercialization Inc., Princeton, NJ, USA; ${ }^{5}$ Mood Disorders Psychopharmacology Unit, University Health Network, University of Toronto, Toronto, ON, Canada
Correspondence: Michael E Thase Department of Psychiatry, Perelman School of Medicine, University of Pennsylvania, 3535 Market Street, Suite 670, Philadelphia, PA 19104, USA

$\mathrm{Tel}+$ I 2157466680

Fax + I 2155730759

Email thase@pennmedicine.upenn.edu
Objective: Episodes of major depressive disorder (MDD) characterized by high levels of anxiety symptoms are less likely to respond to some forms of antidepressant treatment (ADT). This report examines the effects of adjunctive brexpiprazole on depressive symptoms among patients with MDD and anxiety symptoms.

Materials and methods: This was a post hoc analysis of 1,171 patients from the 6-week, randomized, double-blind phases of three studies in adults with MDD and inadequate response to ADTs (NCT01360645, NCT01360632, NCT02196506). Data were pooled for brexpiprazole 2-3 mg/day and for placebo (adjunct to ADT). Montgomery-Åsberg Depression Rating Scale Total score changes were assessed in subgroups of patients with and without anxious distress (based on proxies for the Diagnostic and Statistical Manual of Mental Disorders, Fifth Edition criteria) and anxious depression (defined as a Hamilton Depression Rating Scale Anxiety/ somatization factor score of $\geq 7$ ). Safety was assessed by the incidence of treatment-emergent adverse events (TEAEs).

Results: Benefits were seen for adjunctive brexpiprazole (compared with adjunctive placebo) in both anxiety definition subgroups. For patients with anxious distress, the least squares mean difference $(95 \% \mathrm{CI})$ at week 6 was $-3.00(-4.29,-1.71 ; P<0.0001)$ and, for those without anxious distress, was $-1.38(-2.71,-0.05 ; P=0.043)$. For patients with anxious depression, the difference was $-2.19(-3.60,-0.78 ; P=0.0023)$, compared with $-2.34(-3.58,-1.10 ; P=0.0002)$ for those without anxious depression. The most common TEAEs among patients with anxiety symptoms receiving ADT + brexpiprazole were akathisia, headache, restlessness, somnolence, and weight increase. There were no clinically meaningful differences in the rates of these TEAEs according to the presence or absence of anxiety symptoms.

Conclusion: Adjunctive brexpiprazole $2-3 \mathrm{mg}$ /day may be efficacious in reducing depressive symptoms, and was well tolerated, in patients with clinically relevant anxiety symptoms.

Keywords: depression, double-blind method, random allocation, antidepressants, antipsychotics

\section{Introduction}

Patients with major depressive disorder (MDD) may also experience symptoms of anxiety. Anxiety symptoms are representative of a more severe form of depression, associated with greater illness severity, suicidality, and impaired functioning. ${ }^{1-3}$ Furthermore, anxiety symptoms decrease the likelihood of response to antidepressant treatment (ADT). In a post hoc analysis of clinical studies in patients with inadequate response to prior ADT, patients who met proxy criteria for anxious distress had a lower response rate to prospective ADT than patients who did not meet the criteria. ${ }^{4}$ In the Sequenced 
Treatment Alternatives to Relieve Depression (STAR*D) study, remission was significantly less likely and took longer to occur in patients with anxious depression than in those with non-anxious depression. ${ }^{3}$

The presence and severity of anxiety symptoms in MDD can be assessed using various definitions. The Diagnostic and Statistical Manual of Mental Disorders, Fifth Edition (DSM-5) defines "anxious distress" as the presence of at least two of the following symptoms during a depressive episode: feeling keyed up or tense, feeling unusually restless, difficulty concentrating because of worry, fear that something awful may happen, and feeling that the individual might lose control of himself or herself. ${ }^{5}$ The STAR*D study defined "anxious depression" in a dimensional manner, based on the presence of high levels of anxiety during MDD as measured by the Hamilton Depression Rating Scale (HAM-D) Anxiety/somatization factor. ${ }^{6}$ Thus, whereas the "anxious distress" definition is based upon psychic symptoms, the "anxious depression" definition also includes somatic symptoms. In the International Mood Disorders Collaborative Project, 56\% of patients with MDD met proxy criteria for DSM- 5 anxious distress. ${ }^{1}$ In the STAR *D study, $53 \%$ of outpatients with MDD met the criteria for anxious depression. ${ }^{3}$

Post hoc analyses of randomized controlled trials suggest that adjunctive therapy with atypical antipsychotics, specifically aripiprazole and quetiapine extended-release (XR), may be able to improve depressive symptoms in patients with anxiety symptoms. ${ }^{7,8}$ However, atypical antipsychotics are associated with side effects in MDD, including akathisia, weight gain, and sedation/somnolence, ${ }^{7,9}$ making them unsuitable for some patients. There is a need for additional treatments with efficacy in the difficult-to-treat subpopulation of patients with MDD and anxiety symptoms.

The atypical antipsychotic brexpiprazole is a serotonindopamine activity modulator that acts as a partial agonist at serotonin (5-hydroxytryptamine-1A [5-HT $1 \mathrm{~A}]$ ) and dopamine $\mathrm{D}_{2}$ receptors, and as an antagonist at serotonin $5-\mathrm{HT}_{2 \mathrm{~A}}$ and noradrenaline $\alpha_{1 \mathrm{~B}} / \alpha_{2 \mathrm{C}}$ receptors, all with subnanomolar potency. ${ }^{10}$ The efficacy and safety of brexpiprazole as adjunctive treatment to ADT over 6 weeks have been demonstrated in three placebo-controlled, fixed-dose studies in MDD. ${ }^{11-13}$ As of October 2018, brexpiprazole is approved in the USA, Saudi Arabia, Honduras, and Mexico as an adjunctive therapy to antidepressants for the treatment of MDD in adults.

This article describes a post hoc analysis of three brexpiprazole studies, with the aim of determining the effects of adjunctive brexpiprazole on depressive symptoms among patients with MDD and anxiety symptoms, based on definitions of anxious distress and anxious depression.

\section{Materials and methods Study design and patients}

This was a post hoc analysis of data from the 6-week, randomized, double-blind, placebo-controlled treatment phases of three similarly designed studies (Pyxis [NCT01360645], Polaris [NCT01360632], and Sirius [NCT02196506]). For a full description of the study designs and selection criteria, please refer to the primary manuscripts for these studies. ${ }^{11-13}$

Each of the three studies was conducted in compliance with the International Council for Harmonisation (formerly known as International Conference on Harmonisation) Good Clinical Practice Guideline and with the principles laid out in the Declaration of Helsinki. The protocols were approved by independent ethics committees (Supplementary

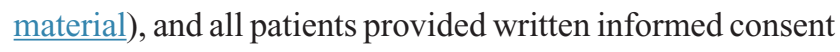
to participate.

The studies recruited outpatients aged 18-65 years meeting the Diagnostic and Statistical Manual of Mental Disorders, Fourth Edition, Text Revision (DSM-IV-TR) ${ }^{14}$ criteria for an episode of MDD of at least 8 weeks' duration. During the current episode, patients must have reported an inadequate response, defined as $<50 \%$ improved on the self-reported Massachusetts General Hospital Antidepressant Treatment Response Questionnaire, ${ }^{15}$ to an adequate trial of between one and three ADTs. Eligible patients had a 17-item HAM-D (HAM-D $\left.{ }_{17}\right)^{16}$ Total score of $\geq 18$ at screening and on the first day of treatment. Patients meeting DSM-IV-TR criteria for certain Axis I disorders (including cognitive, psychotic, and bipolar disorders) were excluded from the studies, although patients with comorbid anxiety disorders were permitted to enroll.

The studies each comprised a screening phase, an 8-week, single-blind, prospective treatment phase, and a 6-week, double-blind, randomized treatment phase for patients who did not respond to prospective treatment. During the prospective treatment phase, patients received open-label ADT (selected by the investigator from a protocol-specified list), together with single-blind placebo. Patients who met criteria for inadequate response to this ADT throughout the 8-week prospective ADT phase were eligible for entry into the randomized treatment phase. Inadequate response was defined as $<50 \%$ reduction in HAM-D ${ }_{17}$ Total score from the start to the end of prospective treatment, a HAM- $\mathrm{D}_{17}$ Total score of $\geq 14$ at the end of prospective treatment, $<50 \%$ reduction in Montgomery-Åsberg Depression Rating 
Scale (MADRS) ${ }^{17}$ Total score from the start of prospective treatment to each 2-weekly interval during the phase, and a Clinical Global Impressions - Improvement ${ }^{18}$ score of $\geq 3$ (ie, minimally improved, no change, or worse) at each 2-weekly interval during the phase.

Patients with inadequate response to prospective ADT were randomized 1:1 to placebo or brexpiprazole $2 \mathrm{mg}$ /day in Pyxis and Sirius, and 1:1:1 to placebo, brexpiprazole $1 \mathrm{mg} /$ day, or brexpiprazole $3 \mathrm{mg} /$ day in Polaris. In all studies, randomized treatment was adjunct to continued ADT. Brexpiprazole was titrated such that all patients received $0.5 \mathrm{mg} /$ day during the first week, $1 \mathrm{mg}$ /day during the second week, and their allocated fixed dose from the third week onward.

\section{Assessments}

The primary efficacy analysis in Pyxis, Polaris, and Sirius was the mean change in MADRS Total score from baseline (ie, randomization) to week 6 of the randomized treatment phase. The MADRS was administered at weeks 1, 2, 3, 4, 5 , and 6 of the randomized phase.

In this post hoc analysis, changes in MADRS Total score were assessed in subgroups of patients according to the presence or absence of anxious distress and anxious depression. Anxious distress was defined, based on proxies for the DSM-5 specifier, ${ }^{19}$ as the presence at baseline of at least two of the following symptoms: feeling keyed up or tense (MADRS item 3 [inner tension] score of $\geq 3$ ), feeling unusually restless (Inventory of Depressive Symptomatology, Self-Report ${ }^{20}$ item 24 [feeling restless] score of $\geq 2$ ), difficulty concentrating because of worry (MADRS item 6 [concentration difficulties] score of $\geq 3$ ), and fear that something awful may happen (HAM-D item 10 [psychic anxiety] score of $\geq 3$ ). No proxy could be found for the DSM-5 criterion "feeling that the individual might lose control of himself or herself", meaning that patients were classified as having anxious distress if they met criteria for at least two out of four, rather than out of five, symptoms.

Anxious depression was defined, based on the definition used by the STAR*D study investigators, ${ }^{6}$ as a score of $\geq 7$ at baseline on the HAM-D Anxiety/somatization factor. ${ }^{21}$ The Anxiety/somatization factor comprises the following six items from the HAM-D: psychic anxiety, somatic anxiety, gastrointestinal somatic symptoms, general somatic symptoms, hypochondriasis, and insight.

Safety was assessed by the incidence of treatmentemergent adverse events (TEAEs) in the subgroups with and without anxiety symptoms.

\section{Statistical analyses}

For this post hoc analysis, data were pooled for patients randomized to brexpiprazole $2 \mathrm{mg} /$ day and $3 \mathrm{mg} /$ day, and for patients randomized to placebo. It was considered appropriate to pool brexpiprazole $2 \mathrm{mg} /$ day and $3 \mathrm{mg} /$ day since, in a previous post hoc analysis, both doses had a similar least squares (LS) mean difference to pooled placebo in MADRS Total score at the majority of time points. ${ }^{22}$ The $1 \mathrm{mg}$ /day dose of brexpiprazole was not included because it is below the recommended minimum dose for the adjunctive treatment of $\operatorname{MDD}(2 \mathrm{mg} /$ day $) .{ }^{23}$

Safety analyses were performed in the population of patients who received at least one dose of brexpiprazole or placebo during the randomized treatment phase. Efficacy analyses were performed in the population of patients who received at least one dose of brexpiprazole or placebo during the randomized treatment phase and had an evaluation for MADRS Total score at baseline and on at least one occasion after baseline.

Cohen's kappa ( $\kappa)$ statistics were used to measure the level of overlap in the distribution of patients with anxious distress and anxious depression at baseline. Baseline MADRS Total scores were compared between subgroups using the Wilcoxon rank sum non-parametric test. To determine the effects of treatment on depressive symptoms, LS mean changes from baseline, standard errors, differences from placebo with 95\% CIs, and Cohen's $d$ effect sizes were calculated for MADRS Total score using a mixed model repeated measures (MMRM) method with model terms of study, treatment, visit, treatment-by-visit, and baselineby-visit interaction, using an unstructured covariance matrix. $P$-values were calculated using a $t$-test derived from MMRM, at the 5\% level (two-sided). To determine the effects of treatment on anxiety symptoms, LS mean changes from baseline, standard errors, and differences from placebo with 95\% CIs were calculated for HAM-D Anxiety/somatization factor score using an analysis of covariance model with treatment and study site as main effects and baseline as covariate, with last observation carried forward (LOCF). Owing to the exploratory nature of the study, corrections for multiple comparisons were not performed.

Numbers needed to treat (NNTs) were calculated based on the risk difference between ADT + brexpiprazole and ADT + placebo with regard to MADRS response. MADRS response was defined as $\geq 50 \%$ reduction from baseline in MADRS Total score (LOCF). The $95 \%$ CIs for NNTs were calculated as the inverse of the $95 \%$ CIs for the risk difference. 
The incidence of TEAEs is presented using descriptive statistics.

\section{Results \\ Patients}

After 8 weeks of prospective ADT, a total of 1,171 patients were randomized to brexpiprazole $2-3 \mathrm{mg} /$ day or placebo, according to the final protocols of the three studies. Of the randomized patients, $57.9 \%(n=678)$ met the criteria for anxious distress and $49.0 \%(\mathrm{n}=574)$ met the criteria for anxious depression. The overlap between patients meeting the criteria for anxious distress and anxious depression is shown in Table 1 (Cohen's $\kappa=0.28$ ). Overall, $7.7 \%$ of patients $(\mathrm{n}=90)$ had a comorbid anxiety disorder.

Of the randomized patients, 1,169 formed the safety population and 1,162 formed the efficacy population. The completion rate was high $(>90 \%)$ and comparable between treatment groups and between anxiety subgroups (Table 2).

In general, baseline demographic and clinical characteristics were similar between treatment and anxiety subgroups (Table 3). However, patients with anxious distress or anxious depression were more likely to be female than those without anxiety symptoms. In addition, the anxious distress and anxious depression subgroups had a more severe illness (higher MADRS Total score) at baseline compared with their corresponding non-anxious subgroups (both $P<0.0001$ ).

\section{Efficacy}

In the subgroup of patients with anxious distress, ADT + brexpiprazole $2-3 \mathrm{mg} /$ day showed benefits $(P<0.05)$ over $\mathrm{ADT}+$ placebo as early as week 1 , as measured by change from baseline in MADRS Total score (Figure 1A). Benefits were maintained throughout the randomized treatment phase, with an LS mean difference at week 6 between ADT + brexpiprazole $2-3 \mathrm{mg} /$ day and ADT + placebo of $-3.00(95 \%$ CI: $-4.29,-1.71$; degrees of freedom [df]: $652 ; P<0.0001$;

Table I Overlap between anxious distress and anxious depression

\begin{tabular}{l|l|l}
\hline \multirow{2}{*}{$\mathbf{( \% )}$} & \multicolumn{2}{|l}{ Anxious depression } \\
\cline { 2 - 3 } & Yes & No \\
\hline Anxious distress & $414(35.4)$ & $264(22.5)$ \\
\hline Yes & $160(13.7)$ & $333(28.4)$ \\
No &
\end{tabular}

Notes: Post hoc analysis of data from three 6-week, randomized, double-blind, placebo-controlled studies in patients with major depressive disorder and inadequate response to antidepressant treatments (Pyxis, Polaris, and Sirius). Data for patients randomized to brexpiprazole $2 \mathrm{mg} /$ day or $3 \mathrm{mg} /$ day, or placebo $(\mathrm{N}=1,17 \mathrm{l})$.
Cohen's $d: 0.35)$. In the subgroup of patients without anxious distress, benefits $(P<0.05)$ for ADT + brexpiprazole $2-3 \mathrm{mg} /$ day were observed from week 3 onward (Figure 1B). The LS mean difference at week 6 between ADT + brexpiprazole 2-3 mg/ day and ADT + placebo was -1.38 (95\% CI: $-2.71,-0.05$; df: 474; $P=0.043$; Cohen's $d$ : 0.18).

Similarly, benefits for ADT + brexpiprazole $2-3 \mathrm{mg} /$ day over ADT + placebo were seen in the subgroup of patients with anxious depression (Figure 1C; LS mean difference at week 6: $-2.19 ; 95 \%$ CI: $-3.60,-0.78$; df: $552 ; P=0.0023$; Cohen's $d: 0.26)$ and the subgroup without anxious depression (Figure 1D; LS mean difference at week 6: -2.34 ; 95\% CI: $-3.58,-1.10$; df: $571 ; P=0.0002$; Cohen's $d: 0.31$ ).

NNTs (95\% CIs) for an additional patient to respond with ADT + brexpiprazole 2-3 mg/day compared with $\mathrm{ADT}+$ placebo were $10(7,28)$ for patients with anxious distress and $44(11,-20)$ for patients without anxious distress. For patients with and without anxious depression, the NNTs were $16(8,-142)$ and $14(7,263)$, respectively.

For the HAM-D Anxiety/somatization factor, among patients with anxious distress, the ADT + brexpiprazole 2-3 $\mathrm{mg}$ /day group changed (improved) by an LS mean (standard error) of $-2.3(0.1)$ points from baseline to week $6(n=334)$, compared with -1.6 (0.1) points in the ADT + placebo group $(\mathrm{n}=318)$, an LS mean difference of -0.70 (95\% CI: -1.03 , $-0.37 ; P<0.0001)$. Among patients with anxious depression, HAM-D Anxiety/somatization factor score changed by -2.8 (0.1) points in the ADT + brexpiprazole $2-3 \mathrm{mg}$ /day group $(n=279)$ compared with $-2.3(0.1)$ points in the ADT + placebo group ( $\mathrm{n}=275)$, an LS mean difference of $-0.49(95 \%$ CI: $-0.88,-0.11 ; P=0.012)$.

\section{Safety}

Treatment with ADT + brexpiprazole 2-3 mg/day was associated with a higher incidence of TEAEs than treatment with $\mathrm{ADT}+$ placebo, for patients with and without anxiety symptoms (Table 4). The incidence of TEAEs was higher among patients with anxious distress than patients without anxious distress, for ADT + brexpiprazole 2-3 mg/day (63.8\% vs $55.5 \%)$ and for ADT + placebo (51.1\% vs $41.8 \%$ ). A similar pattern was observed among patients with and without anxious depression (Table 4).

Among patients with anxious distress and among patients with anxious depression, the TEAEs with incidence $\geq 5 \%$ in the ADT + brexpiprazole 2-3 mg/day group and greater than ADT + placebo were akathisia, restlessness, somnolence, and weight increase (Table 4). Among patients with anxious depression, headache also occurred in $\geq 5 \%$ of 
Table 2 Patient disposition stratified by the presence or absence of anxious distress and anxious depression at baseline

\begin{tabular}{|c|c|c|c|c|c|c|c|c|}
\hline & \multicolumn{2}{|c|}{$\begin{array}{l}\text { Patients with anxious } \\
\text { distress, } \mathbf{n}(\%)\end{array}$} & \multicolumn{2}{|c|}{$\begin{array}{l}\text { Patients without anxious } \\
\text { distress, } \mathbf{n}(\%)\end{array}$} & \multicolumn{2}{|c|}{$\begin{array}{l}\text { Patients with anxious } \\
\text { depression, } \mathbf{n}(\%)\end{array}$} & \multicolumn{2}{|c|}{$\begin{array}{l}\text { Patients without anxious } \\
\text { depression, } n(\%)\end{array}$} \\
\hline & $\begin{array}{l}\text { ADT + } \\
\text { placebo }\end{array}$ & $\begin{array}{l}\text { ADT }+ \\
\text { brexpiprazole }\end{array}$ & $\begin{array}{l}\text { ADT + } \\
\text { placebo }\end{array}$ & $\begin{array}{l}\text { ADT + } \\
\text { brexpiprazole }\end{array}$ & $\begin{array}{l}\text { ADT + } \\
\text { placebo }\end{array}$ & $\begin{array}{l}\text { ADT }+ \\
\text { brexpiprazole }\end{array}$ & $\begin{array}{l}\text { ADT + } \\
\text { placebo }\end{array}$ & $\begin{array}{l}\text { ADT }+ \\
\text { brexpiprazole }\end{array}$ \\
\hline Randomized & $330(100.0)$ & $348(100.0)$ & $256(100.0)$ & $237(100.0)$ & $284(100.0)$ & $290(100.0)$ & $302(100.0)$ & $293(100.0)$ \\
\hline Completed & $310(93.9)$ & $321(92.2)$ & $247(96.5)$ & $218(92.0)$ & $269(94.7)$ & $264(91.0)$ & $288(95.4)$ & $273(93.2)$ \\
\hline Discontinued & $20(6.1)$ & $27(7.8)$ & $9(3.5)$ & $19(8.0)$ & $15(5.3)$ & $26(9.0)$ & $14(4.6)$ & $20(6.8)$ \\
\hline Adverse events & $2(0.6)$ & $10(2.9)$ & $\mathrm{I}(0.4)$ & $8(3.4)$ & $2(0.7)$ & II (3.8) & $\mathrm{I}(0.3)$ & $7(2.4)$ \\
\hline Withdrew consent & $8(2.4)$ & $8(2.3)$ & $6(2.3)$ & $6(2.5)$ & $6(2.1)$ & $7(2.4)$ & $8(2.6)$ & $7(2.4)$ \\
\hline Lost to follow-up & $\mathrm{I}(0.3)$ & $3(0.9)$ & $0(0.0)$ & $\mathrm{I}(0.4)$ & $\mathrm{I}(0.4)$ & $3(1.0)$ & $0(0.0)$ & $\mathrm{I}(0.3)$ \\
\hline $\begin{array}{l}\text { Met withdrawal } \\
\text { criteria }\end{array}$ & $3(0.9)$ & $3(0.9)$ & I $(0.4)$ & $2(0.8)$ & $2(0.7)$ & $3(1.0)$ & $2(0.7)$ & $2(0.7)$ \\
\hline Protocol deviation & $3(0.9)$ & $2(0.6)$ & $\mathrm{I}(0.4)$ & $2(0.8)$ & $2(0.7)$ & $2(0.7)$ & $2(0.7)$ & $2(0.7)$ \\
\hline Lack of efficacy & $2(0.6)$ & $\mathrm{I}(0.3)$ & $0(0.0)$ & $0(0.0)$ & $2(0.7)$ & $0(0.0)$ & $0(0.0)$ & $\mathrm{I}(0.3)$ \\
\hline $\begin{array}{l}\text { Withdrawn by } \\
\text { investigator }\end{array}$ & I $(0.3)$ & $0(0.0)$ & $0(0.0)$ & $0(0.0)$ & $0(0.0)$ & $0(0.0)$ & I $(0.3)$ & $0(0.0)$ \\
\hline Safety population & 329 & 348 & 256 & 236 & 283 & 290 & 302 & 292 \\
\hline Efficacy population & 327 & 343 & 256 & 236 & 282 & 287 & 301 & 290 \\
\hline
\end{tabular}

Notes: Post hoc analysis of data from three 6-week, randomized, double-blind, placebo-controlled studies in patients with major depressive disorder and inadequate response to ADTs (Pyxis, Polaris, and Sirius). Data were pooled for patients randomized to brexpiprazole $2 \mathrm{mg} / \mathrm{day}$ and $3 \mathrm{mg} / \mathrm{day}$, and for patients randomized to placebo. Two patients were excluded from the anxious depression analyses owing to missing anxious depression status.

Abbreviation: ADT, antidepressant treatment.

Table 3 Baseline demographic and clinical characteristics stratified by the presence or absence of anxious distress and anxious depression at baseline

\begin{tabular}{|c|c|c|c|c|c|c|c|c|}
\hline & \multicolumn{2}{|c|}{$\begin{array}{l}\text { Patients with anxious } \\
\text { distress }\end{array}$} & \multicolumn{2}{|c|}{$\begin{array}{l}\text { Patients without anxious } \\
\text { distress }\end{array}$} & \multicolumn{2}{|c|}{$\begin{array}{l}\text { Patients with anxious } \\
\text { depression }\end{array}$} & \multicolumn{2}{|c|}{$\begin{array}{l}\text { Patients without anxious } \\
\text { depression }\end{array}$} \\
\hline & $\begin{array}{l}\text { ADT + } \\
\text { placebo } \\
(n=330)\end{array}$ & $\begin{array}{l}\text { ADT + } \\
\text { brexpiprazole } \\
(n=348)\end{array}$ & $\begin{array}{l}\text { ADT + } \\
\text { placebo } \\
(n=256)\end{array}$ & $\begin{array}{l}\text { ADT + } \\
\text { brexpiprazole } \\
(n=237)\end{array}$ & $\begin{array}{l}\text { ADT + } \\
\text { placebo } \\
(n=284)\end{array}$ & $\begin{array}{l}\text { ADT + } \\
\text { brexpiprazole } \\
(n=290)\end{array}$ & $\begin{array}{l}\text { ADT + } \\
\text { placebo } \\
(n=302)\end{array}$ & $\begin{array}{l}\text { ADT }+ \\
\text { brexpiprazole } \\
(n=293)\end{array}$ \\
\hline \multicolumn{9}{|l|}{ Demographic } \\
\hline $\begin{array}{l}\text { Age (years), } \\
\text { mean (SD) }\end{array}$ & $44.9(12.1)$ & $43.0(12.0)$ & 44.4 (II.5) & $44.8(11.5)$ & $45.2(12.1)$ & $43.7(11.8)$ & $44.2(11.6)$ & 43.7 (11.9) \\
\hline Female, n (\%) & $245(74.2)$ & $258(74.1)$ & $160(62.5)$ & 157 (66.2) & $205(72.2)$ & $212(73.1)$ & $200(66.2)$ & $201(68.6)$ \\
\hline $\begin{array}{l}\text { BMI }\left(\mathrm{kg} / \mathrm{m}^{2}\right) \\
\text { mean }(\mathrm{SD})\end{array}$ & $30.4(7.3)$ & $29.9(6.8)$ & $28.4(6.6)$ & $29.4(6.9)$ & $30.2(7.0)$ & $29.7(6.3)$ & $28.9(7.0)$ & $29.7(7.4)$ \\
\hline White, n (\%) & $286(86.7)$ & $297(85.3)$ & $216(84.4)$ & $209(88.2)$ & $248(87.3)$ & $256(88.3)$ & $254(84.1)$ & $248(84.6)$ \\
\hline \multicolumn{9}{|l|}{ Clinical characteristics } \\
\hline $\begin{array}{l}\text { Duration of current } \\
\text { episode (months), } \\
\text { mean (SD) }\end{array}$ & $17.7(38.1)$ & $16.0(19.7)$ & $16.3(33.4)$ & I3.8 (28.4) & $18.0(40.9)$ & $14.9(22.5)$ & I6.I (31.1) & $15.3(24.8)$ \\
\hline $\begin{array}{l}\text { Recurrent } \\
\text { episode, } n(\%)\end{array}$ & $284(86.1)$ & $298(85.6)$ & $216(84.4)$ & $203(85.7)$ & $246(86.6)$ & $252(86.9)$ & $254(84.1)$ & $247(84.3)$ \\
\hline $\begin{array}{l}\text { Number of lifetime } \\
\text { episodes, } \\
\text { mean (SD) }\end{array}$ & $3.7(3.8)$ & $3.4(2.6)$ & $3.3(2.0)$ & $3.4(2.7)$ & $3.4(2.4)$ & $3.4(2.6)$ & $3.6(3.8)$ & $3.4(2.6)$ \\
\hline MADRS Total & $29.1(5.4)$ & $28.9(5.0)$ & $23.5(4.5)$ & $23.8(4.9)$ & $28.6(5.9)$ & $28.9(5.5)$ & $24.8(4.8)$ & $24.6(4.7)$ \\
\hline score, mean (SD) & $(n=327)$ & $(n=343)$ & $(n=256)$ & $(n=236)$ & $(n=282)$ & $(n=287)$ & $(n=30 I)$ & $(n=290)$ \\
\hline HAM-D Anxiety/ & $7.1(1.7)$ & $7.0(1.7)$ & $5.7(1.6)$ & $5.9(1.6)$ & $8.0(1.1)$ & $8.0(1.1)$ & $5.1(1.0)$ & $5.2(1.0)$ \\
\hline $\begin{array}{l}\text { somatization factor } \\
\text { score, mean (SD) }\end{array}$ & $(n=3 \mid 8)$ & $(n=334)$ & $(n=253)$ & $(n=230)$ & $(n=275)$ & $(n=279)$ & $(n=296)$ & $(n=285)$ \\
\hline
\end{tabular}

Notes: Post hoc analysis of data from three 6-week, randomized, double-blind, placebo-controlled studies in patients with major depressive disorder and inadequate response to ADTs (Pyxis, Polaris, and Sirius). Data were pooled for patients randomized to brexpiprazole $2 \mathrm{mg} /$ day and $3 \mathrm{mg} /$ day, and for patients randomized to placebo. Abbreviations: ADT, antidepressant treatment; BMI, body mass index; HAM-D, Hamilton Depression Rating Scale; MADRS, Montgomery-Åsberg Depression Rating Scale. 
A

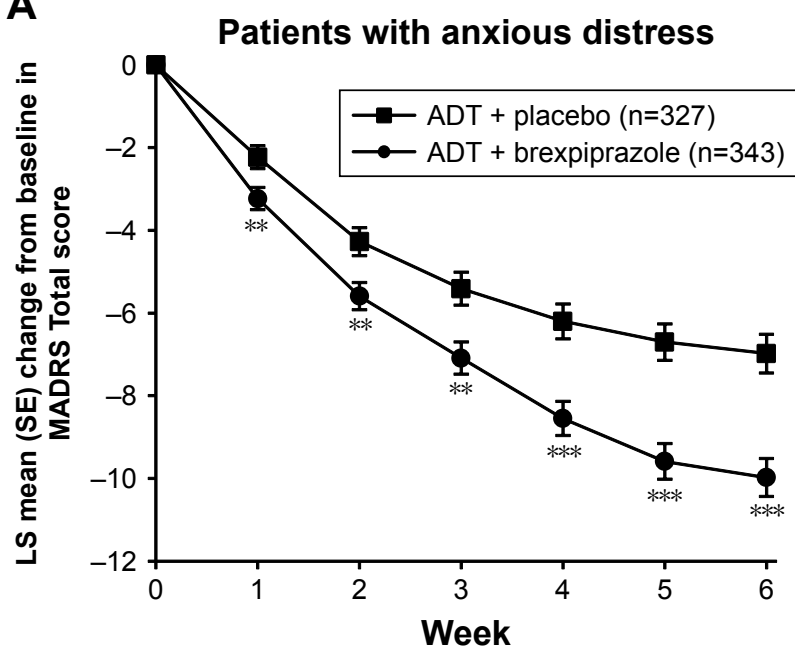

C

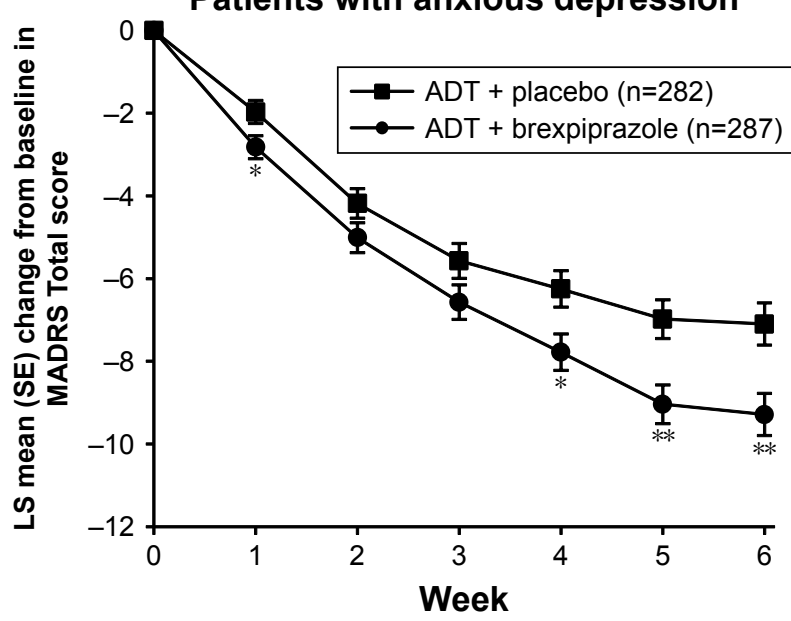

B

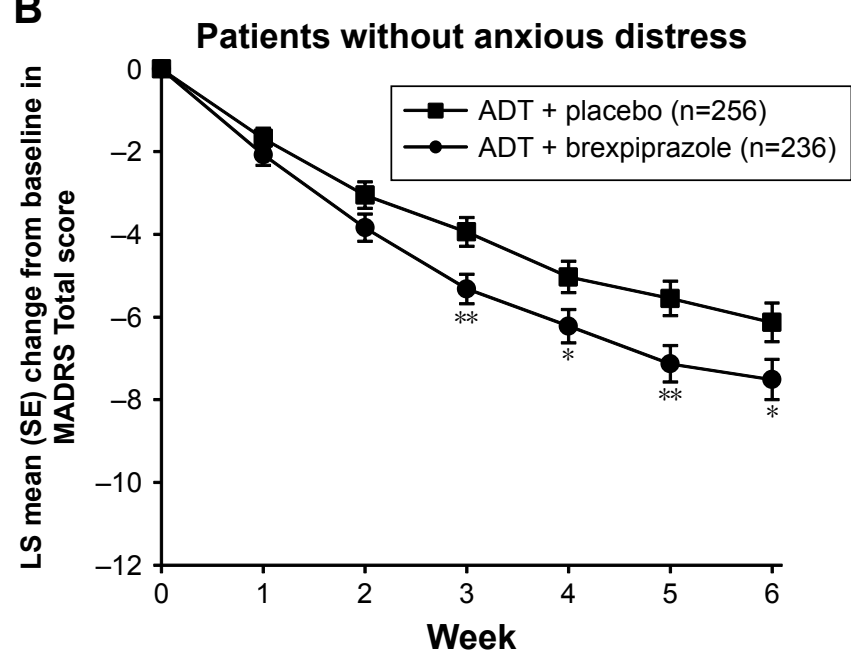

D

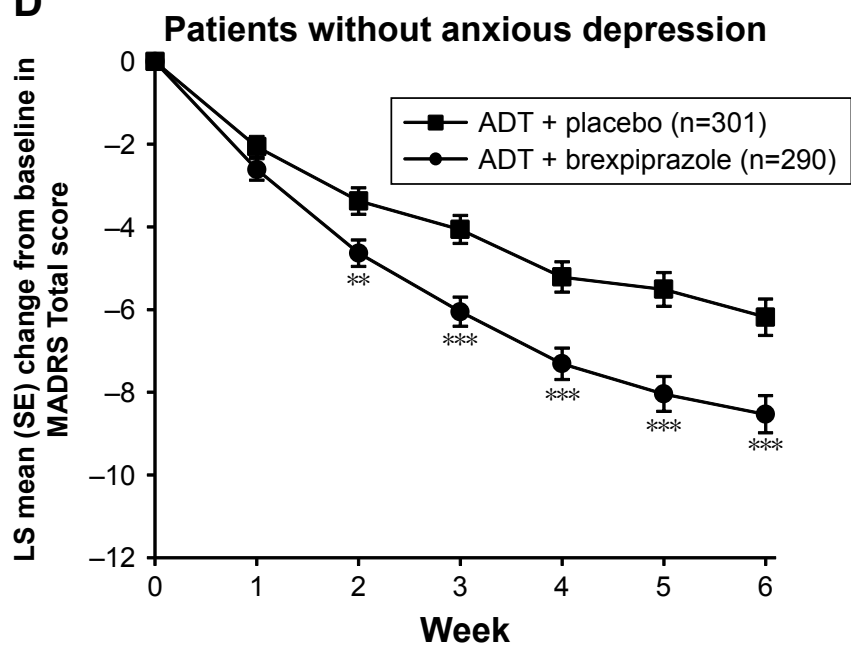

Figure I Effect of brexpiprazole and placebo as adjunct to ADT on MADRS Total score, stratified by the presence or absence of anxious distress (A, B) and anxious depression (C, D) at baseline.

Notes: $* P<0.05,{ }^{*} P<0.01$, $* * * P<0.001$ vs placebo. Baseline MADRS Total scores (ADT + placebo, ADT + brexpiprazole): (A) 29.1, 28.9; (B) 23.5, 23.8; (C) 28.6, 28.9; (D) 24.8, 24.6. Post hoc analysis of data from three 6-week, randomized, double-blind, placebo-controlled studies in patients with major depressive disorder and inadequate response to ADTs (Pyxis, Polaris, and Sirius). Data were pooled for patients randomized to brexpiprazole $2 \mathrm{mg} /$ day and $3 \mathrm{mg} / \mathrm{day}$, and for patients randomized to placebo. Abbreviations: ADT, antidepressant treatment; LS, least squares; MADRS, Montgomery-Åsberg Depression Rating Scale; SE, standard error.

Table 4 TEAEs stratified by the presence or absence of anxious distress and anxious depression at baseline

\begin{tabular}{|c|c|c|c|c|c|c|c|c|}
\hline & \multicolumn{2}{|c|}{$\begin{array}{l}\text { Patients with anxious } \\
\text { distress, } \mathbf{n}(\%)\end{array}$} & \multicolumn{2}{|c|}{$\begin{array}{l}\text { Patients without anxious } \\
\text { distress, } \mathbf{n}(\%)\end{array}$} & \multicolumn{2}{|c|}{$\begin{array}{l}\text { Patients with anxious } \\
\text { depression, } \mathbf{n}(\%)\end{array}$} & \multicolumn{2}{|c|}{$\begin{array}{l}\text { Patients without anxious } \\
\text { depression, } \mathbf{n}(\%)\end{array}$} \\
\hline & $\begin{array}{l}\text { ADT + } \\
\text { placebo } \\
(n=329)\end{array}$ & $\begin{array}{l}\text { ADT }+ \\
\text { brexpiprazole } \\
(n=348)\end{array}$ & $\begin{array}{l}\text { ADT + } \\
\text { placebo } \\
(n=256)\end{array}$ & $\begin{array}{l}\text { ADT + } \\
\text { brexpiprazole } \\
(n=236)\end{array}$ & $\begin{array}{l}\text { ADT + } \\
\text { placebo } \\
(n=283)\end{array}$ & $\begin{array}{l}\text { ADT + } \\
\text { brexpiprazole } \\
(n=290)\end{array}$ & $\begin{array}{l}\text { ADT + } \\
\text { placebo } \\
(n=302)\end{array}$ & $\begin{array}{l}\text { ADT }+ \\
\text { brexpiprazole } \\
(n=292)\end{array}$ \\
\hline At least one TEAE & $168(5 I .1)$ & $222(63.8)$ & $107(41.8)$ & $13 \mid(55.5)$ & $145(5 I .2)$ & $181(62.4)$ & $130(43.0)$ & $170(58.2)$ \\
\hline \multicolumn{9}{|c|}{ TEAEs occurring in $\geq 5 \%$ of patients in any ADT + brexpiprazole group } \\
\hline Akathisia & $12(3.6)$ & $36(10.3)$ & $5(2.0)$ & $20(8.5)$ & $9(3.2)$ & $26(9.0)$ & $8(2.6)$ & $30(10.3)$ \\
\hline Headache & $27(8.2)$ & $17(4.9)$ & II (4.3) & $10(4.2)$ & $19(6.7)$ & $16(5.5)$ & $19(6.3)$ & II (3.8) \\
\hline Restlessness & $2(0.6)$ & $24(6.9)$ & $2(0.8)$ & $8(3.4)$ & $3(1.1)$ & $20(6.9)$ & $I(0.3)$ & $12(4.1)$ \\
\hline Somnolence & $7(2.1)$ & $19(5.5)$ & $\mathrm{I}(0.4)$ & $10(4.2)$ & $8(2.8)$ & $18(6.2)$ & $0(0.0)$ & II (3.8) \\
\hline Weight increase & $6(1.8)$ & $22(6.3)$ & $3(1.2)$ & $14(5.9)$ & $4(1.4)$ & $19(6.6)$ & $5(1.7)$ & $16(5.5)$ \\
\hline
\end{tabular}

Notes: Post hoc analysis of data from three 6-week, randomized, double-blind, placebo-controlled studies in patients with major depressive disorder and inadequate response to ADTs (Pyxis, Polaris, and Sirius). Data were pooled for patients randomized to brexpiprazole $2 \mathrm{mg} /$ day and $3 \mathrm{mg} /$ day, and for patients randomized to placebo. Abbreviations: ADT, antidepressant treatment; TEAE, treatment-emergent adverse event. 
patients receiving ADT + brexpiprazole, albeit at a lower incidence than with ADT + placebo. For patients without anxious distress and for patients without anxious depression, the TEAEs of akathisia and weight increase had an incidence of $\geq 5 \%$ in the ADT + brexpiprazole $2-3 \mathrm{mg} /$ day group and greater than ADT + placebo. Apart from akathisia and restlessness, other activating TEAEs (eg, agitation, anxiety, insomnia) occurred at an incidence of $<5 \%$ in all ADT + brexpiprazole groups.

\section{Discussion}

In this pooled analysis of three randomized, controlled studies in MDD, brexpiprazole $2-3 \mathrm{mg} /$ day as adjunct to ADT was efficacious in patients with anxiety symptoms, regardless of whether they were categorized using the DSM-5 criteria for anxious distress or the STAR*D definition of anxious depression. Cohen's $d$ effect sizes for the mean drug vs placebo difference at study endpoint were 0.35 among patients with anxious distress and 0.26 among patients with anxious depression, indicating that adjunctive brexpiprazole therapy was comparably effective in both subgroups.

Despite the apparent similarity of the anxious distress and anxious depression definitions, the Cohen's $\kappa$ of 0.28 indicated that there was a surprisingly low level of overlap between the groups. There are two key differences between the definitions: 1) content, because the anxious depression definition includes somatic as well as psychic symptoms; and 2) time frame, because HAM-D items are rated for the past week, whereas the DSM-5 anxious distress specifier requires the symptoms be present for the majority of the depressive episode. ${ }^{5,24}$ Although the latter difference is not applicable to the proxies used in the present analysis, a study using the DSM-5 Anxious Distress Specifier Interview found a similarly low association between the DSM-5 and HAM-D subtyping approaches $(\kappa=0.21)$, concluding that while both definitions of anxious depression are useful to predict outcomes, comorbidities, and longitudinal course, the definitions are not interchangeable. ${ }^{24}$

The observed benefits of adjunctive brexpiprazole in patients with anxiety are consistent with the results of an exploratory, 6-week, open-label study, in which symptoms of depression and anxiety improved with flexible-dose brexpiprazole treatment among patients with MDD and anxiety symptoms (defined as a Hamilton Anxiety Rating Scale [HAM-A ${ }^{25}$ Total score of $\left.\geq 20\right) .{ }^{26}$

Other post hoc analyses of adjunctive therapy with atypical antipsychotics in patients with anxious depression have shown benefits on MADRS scores for adjunctive aripiprazole ${ }^{7}$ and adjunctive quetiapine $\mathrm{XR} .{ }^{8}$ In these studies, the drug-placebo differences in MADRS Total score change at endpoint were $\sim 2.6$ points for aripiprazole and $\sim 2.7-3.3$ points for quetiapine XR (depending on dose; effect size: 0.28-0.35), a comparable magnitude to that observed with adjunctive brexpiprazole in the present analyses. In addition, a number of studies have shown that atypical antipsychotics are able to reduce anxiety symptoms in patients with MDD, as measured by the HAM-A. ${ }^{27}$ Although the HAM-A was not a part of the present analysis, ADT + brexpiprazole showed a benefit on the HAM-D Anxiety/somatization factor, suggesting that brexpiprazole may be efficacious at treating anxiety symptoms in depression.

There is a clinical need for efficacious treatments for patients with MDD and anxiety symptoms, since these patients are less likely to respond to ADT than those without anxiety symptoms. ${ }^{3,4}$ In clinical practice, the presence of anxious mood in patients with MDD is one of several symptoms that drives the decision to prescribe an adjunctive antipsychotic treatment. ${ }^{28}$ In this post hoc analysis, adjunctive brexpiprazole was efficacious even when anxiety symptoms were present.

In general, brexpiprazole was well tolerated in patients with or without anxiety symptoms. Among patients receiving brexpiprazole, akathisia was the most common TEAE regardless of the presence of anxiety symptoms, with an incidence of $\leq 10 \%$ in each group. Overall, for patients treated with ADT + brexpiprazole 2-3 mg/day, there were no clinically meaningful differences in the rates of the most common TEAEs according to the presence or absence of anxious distress and anxious depression.

Limitations of the analysis include its post hoc nature and the use of proxies for the DSM-5 anxious distress specifier. The proxies for "feeling keyed up or tense" and "difficulty concentrating because of worry" were based on MADRS items, meaning that they were not independent with regard to MADRS Total score. As expected, patients with anxiety symptoms had a higher MADRS Total score at baseline, and the effects of anxiety and illness severity on outcomes were not differentiated. Finally, as an exploratory analysis that should be investigated further in future studies, adjustments were not made for multiple comparisons, potentially inflating the type I error rate. ${ }^{29}$

\section{Conclusion}

These data indicate that adjunctive brexpiprazole $2-3 \mathrm{mg} /$ day is efficacious in reducing depressive symptoms in patients with clinically relevant anxiety symptoms who have not 
responded to antidepressant monotherapy. Adjunctive brexpiprazole was well tolerated in patients with clinically relevant anxiety symptoms.

\section{Data sharing statement}

The authors confirm that the data supporting the findings of this study are available within the article.

\section{Acknowledgments}

This work was supported by Otsuka Pharmaceutical Development \& Commercialization Inc. (Princeton, NJ, USA) and H. Lundbeck A/S (Valby, Denmark). The sponsors were responsible for the study design and conduct, and the collection, management, analysis, and interpretation of the data; and were involved in the writing and reviewing of this article. Writing support was provided by Chris Watling, $\mathrm{PhD}$, assisted by his colleagues at Cambridge Medical Communication Ltd (Cambridge, UK), and funded by Otsuka Pharmaceutical Development \& Commercialization Inc. and H. Lundbeck A/S.

\section{Author contributions}

All authors contributed toward data analysis and interpretation, and drafting and revising the paper, approved the final version to be published, and agree to be accountable for all aspects of the work.

\section{Disclosure}

MET reports the following relationships over the past 3 years: advisor/consultant: Acadia, Alkermes, Allergan (Forest, Naurex), AstraZeneca, Cerecor, Eli Lilly, Fabre-Kramer, Gerson Lehrman Group, Guidepoint Global, Johnson \& Johnson (Janssen, Ortho-McNeil), Lundbeck, MedAvante, Merck, Moksha8, Nestlé (Pamlab), Novartis, Otsuka, Pfizer, Shire, Sunovion, and Takeda; grant support: Acadia, Agency for Healthcare Research and Quality, Alkermes, Assurex, Avanir, Forest, Intra-Cellular, Janssen, National Institute of Mental Health, Otsuka, PCORI, and Takeda; equity holdings: MedAvante Inc.; royalties: American Psychiatric Press, Guilford Publications, Herald House, W.W. Norton \& Company Inc.; employment (spouse): Peloton Advantage, which does business with AstraZeneca, GSK, and Pfizer. EW was a full-time employee of $\mathrm{H}$. Lundbeck $\mathrm{A} / \mathrm{S}$ at the time of this work. PZ and CW are full-time employees of Otsuka Pharmaceutical Development \& Commercialization Inc. RSM reports grants from Allergan, AstraZeneca, BristolMyers, Janssen-Ortho, Lundbeck, Neurocrine, Otsuka, Pfizer, Purdue, Shire, Sunovion, and Takeda. The authors report no other conflicts of interest in this work.

\section{References}

1. McIntyre RS, Woldeyohannes HO, Soczynska JK, et al. The prevalence and clinical characteristics associated with Diagnostic and Statistical Manual Version-5-defined anxious distress specifier in adults with major depressive disorder: results from the International Mood Disorders Collaborative Project. Ther Adv Chronic Dis. 2016;7(3):153-159.

2. Zimmerman M, Chelminski I, Young D, Dalrymple K, Walsh E, Rosenstein L. A clinically useful self-report measure of the DSM-5 anxious distress specifier for major depressive disorder. J Clin Psychiatry. 2014;75(6):601-607.

3. Fava M, Rush AJ, Alpert JE, et al. Difference in treatment outcome in outpatients with anxious versus nonanxious depression: a STAR*D report. Am J Psychiatry. 2008;165(3):342-351.

4. Brown TM, Dibenedetti DB, Danchenko N, Weiller E, Fava M. Symptoms of anxiety and irritability in patients with major depressive disorder. J Depress Anxiety. 2016;5(3):237.

5. American Psychiatric Association. Diagnostic and Statistical Manual of Mental Disorders. 5th ed. Arlington, VA: American Psychiatric Association; 2013.

6. Fava M, Alpert JE, Carmin CN, et al. Clinical correlates and symptom patterns of anxious depression among patients with major depressive disorder in STAR*D. Psychol Med. 2004;34(7):1299-1308.

7. Trivedi MH, Thase ME, Fava M, et al. Adjunctive aripiprazole in major depressive disorder: analysis of efficacy and safety in patients with anxious and atypical features. J Clin Psychiatry. 2008;69(12):1928-1936.

8. Bandelow B, Bauer M, Vieta E, et al. Extended release quetiapine fumarate as adjunct to antidepressant therapy in patients with major depressive disorder: pooled analyses of data in patients with anxious depression versus low levels of anxiety at baseline. World J Biol Psychiatry. 2014;15(2):155-166.

9. Bauer M, El-Khalili N, Datto C, Szamosi J, Eriksson H. A pooled analysis of two randomised, placebo-controlled studies of extended release quetiapine fumarate adjunctive to antidepressant therapy in patients with major depressive disorder. J Affect Disord. 2010; 127(1-3): 19-30.

10. Maeda K, Sugino H, Akazawa H, et al. Brexpiprazole I: in vitro and in vivo characterization of a novel serotonin-dopamine activity modulator. J Pharmacol Exp Ther. 2014;350(3):589-604.

11. Thase ME, Youakim JM, Skuban A, et al. Efficacy and safety of adjunctive brexpiprazole $2 \mathrm{mg}$ in major depressive disorder: a phase 3 , randomized, placebo-controlled study in patients with inadequate response to antidepressants. J Clin Psychiatry. 2015;76(9):1224-1231.

12. Thase ME, Youakim JM, Skuban A, et al. Adjunctive brexpiprazole 1 and $3 \mathrm{mg}$ for patients with major depressive disorder following inadequate response to antidepressants: a phase 3, randomized, double-blind study. J Clin Psychiatry. 2015;76(9):1232-1240.

13. Hobart M, Skuban A, Zhang P, et al. A randomized, placebo-controlled study of the efficacy and safety of fixed-dose brexpiprazole $2 \mathrm{mg} / \mathrm{d}$ as adjunctive treatment of adults with major depressive disorder. J Clin Psychiatry. 2018;79(4). pii: $17 \mathrm{~m} 12058$.

14. American Psychiatric Association. Diagnostic and Statistical Manual of Mental Disorders. 4th ed text revision. Washington, DC: American Psychiatric Association; 2000.

15. Chandler GM, Iosifescu DV, Pollack MH, Targum SD, Fava M. RESEARCH: validation of the Massachusetts General Hospital Antidepressant Treatment History Questionnaire (ATRQ). CNS Neurosci Ther. 2010;16(5):322-325.

16. Hamilton M. A rating scale for depression. J Neurol Neurosurg Psychiatry. 1960;23:56-62.

17. Montgomery SA, Åsberg M. A new depression scale designed to be sensitive to change. Br J Psychiatry. 1979;134:382-389.

18. Guy W. ECDEU Assessment Manual for Psychopharmacology. Revised. Rockville, MD: National Institute of Mental Health; 1976.

19. McIntyre RS, Weiller E, Zhang P, Weiss C. Brexpiprazole as adjunctive treatment of major depressive disorder with anxious distress: results from a post-hoc analysis of two randomised controlled trials. $J$ Affect Disord. 2016;201:116-123. 
20. Rush AJ, Gullion CM, Basco MR, Jarrett RB, Trivedi MH. The inventory of depressive symptomatology (IDS): psychometric properties. Psychol Med. 1996;26(3):477-486.

21. Cleary P, Guy W. Factor analysis of the Hamilton Depression Scale. Drugs Exp Clin Res. 1977;1(1-2):115-120.

22. Thase ME, Zhang P, Skuban A, et al. Efficacy of adjunctive brexpiprazole in patients with major depressive disorder: a clinical overview. Curr Psychiatry Rev. 2016;12(3):291-301.

23. Rexulti ${ }^{\circledR}$ (Brexpiprazole) Tablets, for Oral Use [Prescribing Information]. Tokyo: Otsuka Pharmaceutical Co., Ltd; 2018.

24. Zimmerman M, Clark H, McGonigal P, Harris L, Guzman Holst C, Martin J. Relationship between the DSM-5 anxious distress specifier and the Hamilton Depression Rating Scale anxiety/somatization factor. J Nerv Ment Dis. 2018;206(2):152-154.

25. Hamilton M. The assessment of anxiety states by rating. $\mathrm{Br} \mathrm{J} \mathrm{Med}$ Psychol. 1959;32(1):50-55.
26. Davis LL, Ota A, Perry P, Tsuneyoshi K, Weiller E, Baker RA. Adjunctive brexpiprazole in patients with major depressive disorder and anxiety symptoms: an exploratory study. Brain Behav. 2016; 6(10):e00520.

27. Komossa K, Depping AM, Gaudchau A, Kissling W, Leucht S. Secondgeneration antipsychotics for major depressive disorder and dysthymia. Cochrane Database Syst Rev. 2010;12:CD008121.

28. McIntyre RS, Weiller E. Real-world determinants of adjunctive antipsychotic prescribing for patients with major depressive disorder and inadequate response to antidepressants: a case review study. Adv Ther. 2015;32(5):429-444.

29. Li G, Taljaard M, van den Heuvel ER, et al. An introduction to multiplicity issues in clinical trials: the what, why, when and how. Int $J$ Epidemiol. 2017;46(2):746-755.
Neuropsychiatric Disease and Treatment

\section{Publish your work in this journal}

Neuropsychiatric Disease and Treatment is an international, peerreviewed journal of clinical therapeutics and pharmacology focusing on concise rapid reporting of clinical or pre-clinical studies on a range of neuropsychiatric and neurological disorders. This journa is indexed on PubMed Central, the 'PsycINFO' database and CAS,

\section{Dovepress}

and is the official journal of The International Neuropsychiatric Association (INA). The manuscript management system is completely online and includes a very quick and fair peer-review system, which is all easy to use. Visit http://www.dovepress.com/testimonials.php to read real quotes from published authors.

Submit your manuscript here: http://www.dovepress.com/neuropsychiatric-disease-and-treatment-journal 